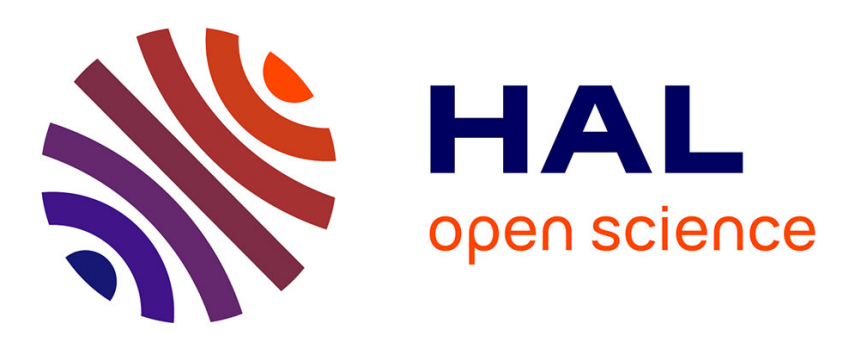

\title{
Advanced Electrical characterisation of high voltage 4H-SiC PiN diodes
}

Besar Asllani, Dominique Planson, Pascal Bevilacqua, Jean-Baptiste Fonder, Beverley Choucoutou, Hervé Morel, L. Phung

\section{- To cite this version:}

Besar Asllani, Dominique Planson, Pascal Bevilacqua, Jean-Baptiste Fonder, Beverley Choucoutou, et al.. Advanced Electrical characterisation of high voltage 4H-SiC PiN diodes. Materials Science Forum, 2019, 963, pp.567-571. 10.4028/www.scientific.net/MSF.963.567 . hal-02060334

\section{HAL Id: hal-02060334 https://hal.science/hal-02060334}

Submitted on 7 Mar 2019

HAL is a multi-disciplinary open access archive for the deposit and dissemination of scientific research documents, whether they are published or not. The documents may come from teaching and research institutions in France or abroad, or from public or private research centers.
L'archive ouverte pluridisciplinaire HAL, est destinée au dépôt et à la diffusion de documents scientifiques de niveau recherche, publiés ou non, émanant des établissements d'enseignement et de recherche français ou étrangers, des laboratoires publics ou privés. 


\title{
Advanced Electrical characterisation of high voltage $4 \mathrm{H}-\mathrm{SiC}$ PiN diodes
}

\author{
B. Asllani ${ }^{1,2}$ a*,D. Planson ${ }^{1, b}$, P. Bevilacqua ${ }^{1, ~ c}$, J.B. Fonder ${ }^{3, d}$, \\ B. Choucoutou ${ }^{4, e}, \mathrm{H}$. Morel ${ }^{1, f}$ and L.V. Phung ${ }^{1, g}$ \\ ${ }^{1}$ Univ Lyon, INSA Lyon, CNRS, Ampère, F-69621 Lyon, France \\ ${ }^{2}$ PEMC Group, University of Nottingham, Nottingham NG7 2RD, UK \\ ${ }^{3}$ CALY Technologies, 56 Bd. Niels Bohr, 69603 Villeurbanne Cedex, France \\ ${ }^{4}$ Supergrid Institute, 23 Rue Cyprian, BP1321, 69611, Villeurbanne Cedex, France

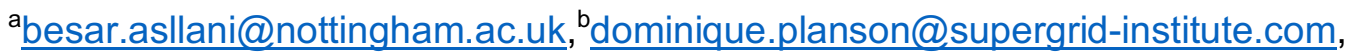

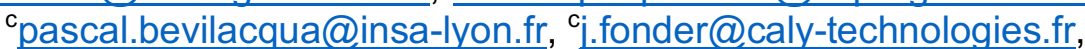

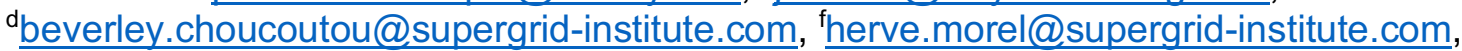 \\ gluong-viet.phung@insa-lyon.fr
}

Keywords: $4 \mathrm{H}-\mathrm{SiC}$ bipolar diode, device processing, high voltage device, high current stress, double-pulse test, device robustness

Abstract. This paper reports the design, the processing, the static characterisation, the switching behaviour and the high current stress test of $10 \mathrm{kV}$ aimed $4 \mathrm{H}-\mathrm{SiC}$ bipolar diodes. The actual breakdown voltage of the selected devices is between $7 \mathrm{kV}$ and $8 \mathrm{kV}$. The switching characterisations show a good behaviour with a $t_{\mathrm{rr}}$ of only $90 \mathrm{~ns}$. No degradation was observed after the application of 10000 high current pulses during the stress tests.

\section{Introduction}

4H-SiC bipolar diodes are key devices for high voltage converters and smart grids applications [1]. Although the unipolar-bipolar limit remains to be defined, bipolar devices cannot be replaced by the unipolar counterparts when it comes to high voltage applications. This is a consequence of the high current injection capabilities of bipolar devices, which make them capable of higher surge current robustness.

In the frame of SuperGrid Institute (SGI), high voltage bipolar devices have been designed, fabricated and characterised.

\section{Device Processing}

PiN diodes were fabricated by Ion Beam Services on $\mathrm{N}^{+}$substrates, using a $110 \mu \mathrm{m}$ thick epilayer with a doping concentration of $7 \times 10^{14} \mathrm{~cm}^{-3}$. A cross-section of the PiN diode is shown in Fig. 1.

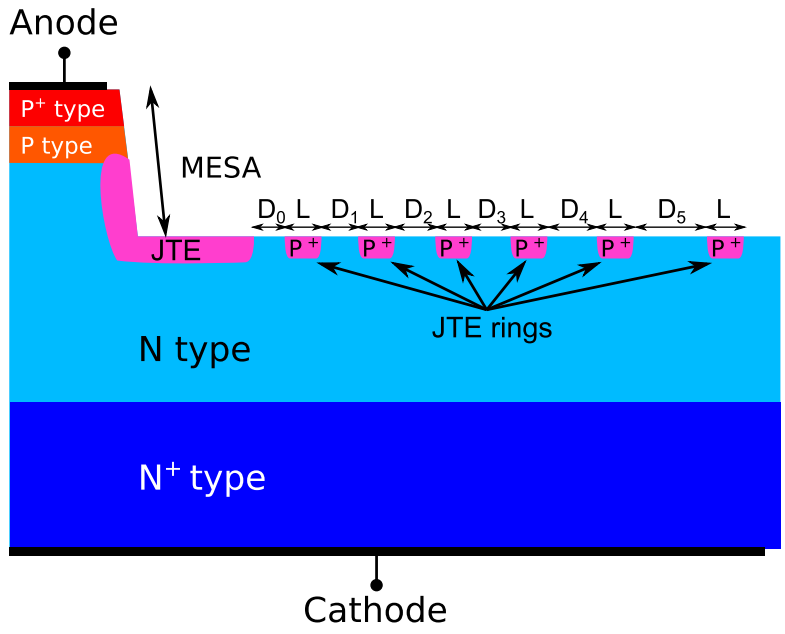

Fig. 1 - Schematic cross-view of the fabricated PiN diode.

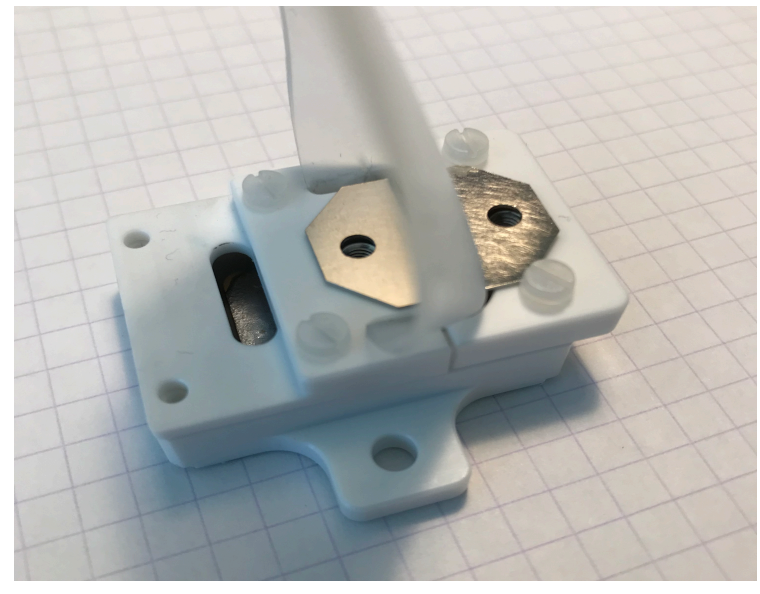

Fig. $2-10 \mathrm{kV}$ capable packaging. 
The edge termination of the PiN diodes includes MESA and Junction Termination Extension (JTE) $400 \mu \mathrm{m}$ long surrounded by 6 JTE-rings with increasing spacing between them $\left(\mathrm{D}_{\mathrm{i}}\right)$. The diode is squared with a length of $7.7 \mathrm{~mm}\left(0.6 \mathrm{~cm}^{2}\right)$ of radius curvature on the corners fixed to $600 \mu \mathrm{m}$. After characterising all devices at wafer level, the best ones were diced and packaged in a specific package developed by DeepConcept company [2] as shown in Fig. 2.

\section{Device Characterisation and Stressing}

The characterisation and stress cycling is done as shown in figure 3. After a full static and switching characterisation, the device is mounted on the rig and is submitted to the stress protocol. The forward and reverse characterisation is done after 1, 10,100, 1000 and 10000 pulses of high current. At the end of the stress test, the electrical parameters of the devices are checked for any stress caused variation. Further tests can be done to analyse how much the robustness and reliability of the device has been affected.

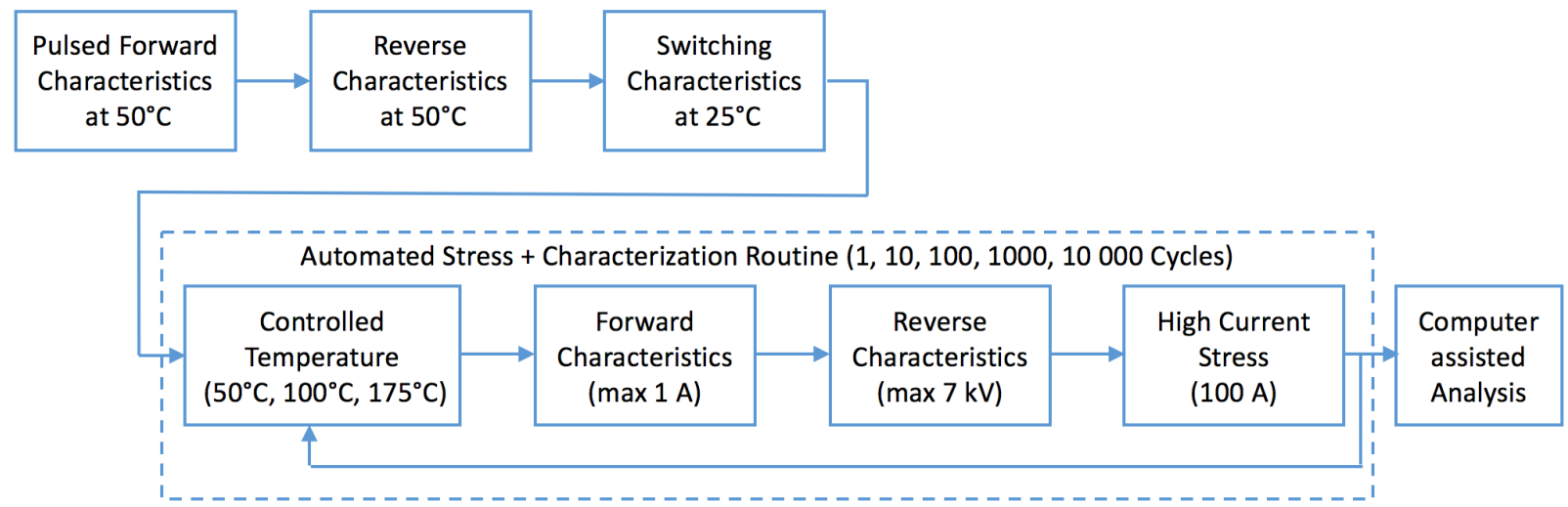

Fig. 3 - The specific characterisation procedure including the stress test that has been applied to the diodes.

The full characterisation and stress automated rig is fully described in [3]. The current capabilities have been doubled and the reverse bias voltage is now limited to $8 \mathrm{kV}$.

Static Characteristics. Forward and reverse characteristics of the diode are shown in Fig. 4 and Fig. 5 respectively. The measurements have been carried out at $50^{\circ} \mathrm{C}, 100^{\circ} \mathrm{C}$ and $175^{\circ} \mathrm{C}$. The presented device has a threshold voltage of $3 \mathrm{~V}$ at $1 \mathrm{~A}$, a dynamic resistance of $69 \mathrm{~m} \Omega$ and a breakdown voltage of $6.8 \mathrm{kV}$.

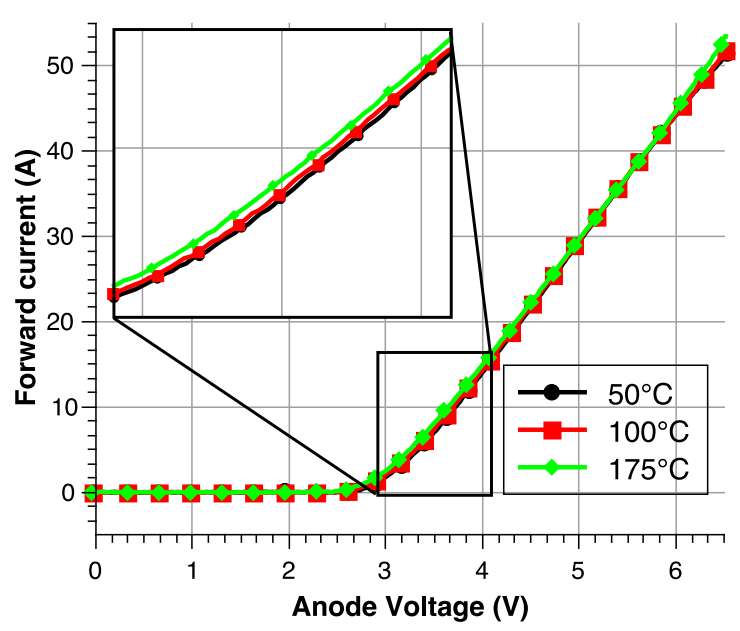

Fig. 4 - Pulsed $(50 \mu \mathrm{s})$ Forward Characteristics of the SGI $4 \mathrm{H}-\mathrm{SiC}$ PiN diode.

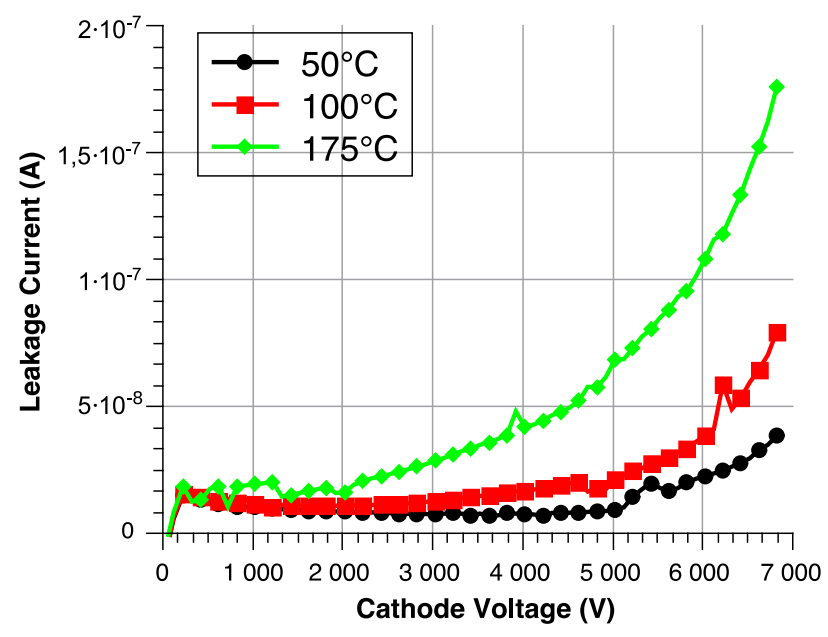

Fig. 5 - Reverse Characteristics of the SGI $4 \mathrm{H}-\mathrm{SiC} \mathrm{PiN}$ diode. 
Switching Measurements. Double Pulse Tests (DPT) [4,5] have been achieved on unstressed components. The DPT circuit was adapted to high voltage switching. The high voltage controlled switch (15 kV $1200 \mathrm{~A})$ is supplied by Comeca [6]. It is a serial and parallel assembly of IGBTs.

Fig. 6 shows the turn-off measurement for two forward currents. The constant di/dt obtained in the first phase of the turn-off show the quality of the DPT circuit.

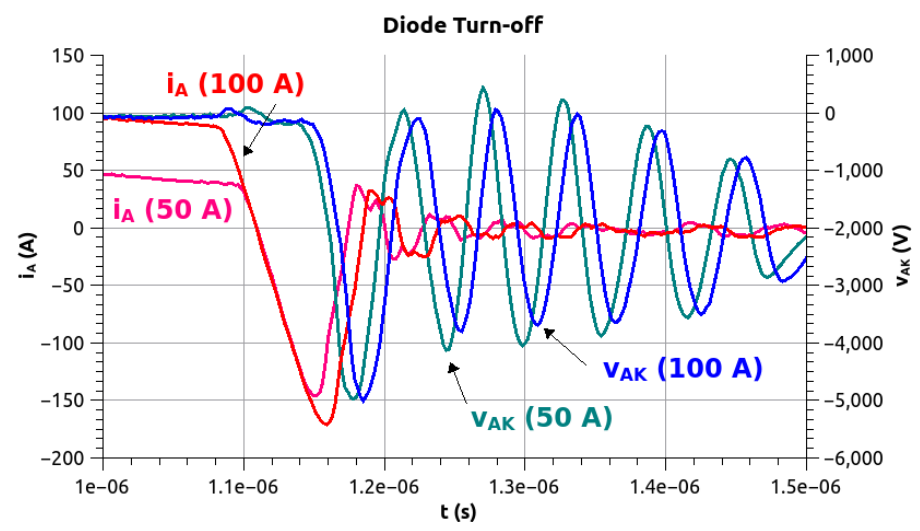

Fig. 6 - DPT turn-off measurements for different forward current $i_{F}(50 \mathrm{~A}$ and $100 \mathrm{~A})$ for a reverse applied voltage $\mathrm{V}_{\mathrm{R}}=2.0 \mathrm{kV}$. The $\mathrm{di} / \mathrm{dt}$ is clearly constant during the turn-off first phase with is classical in PIN turn-off.

Fig. 7 shows the turn-off measurement for three reverse applied voltage. The maximal reverse voltage $\mathrm{V}_{\mathrm{RM}}$ reaches $6.8 \mathrm{kV}$.

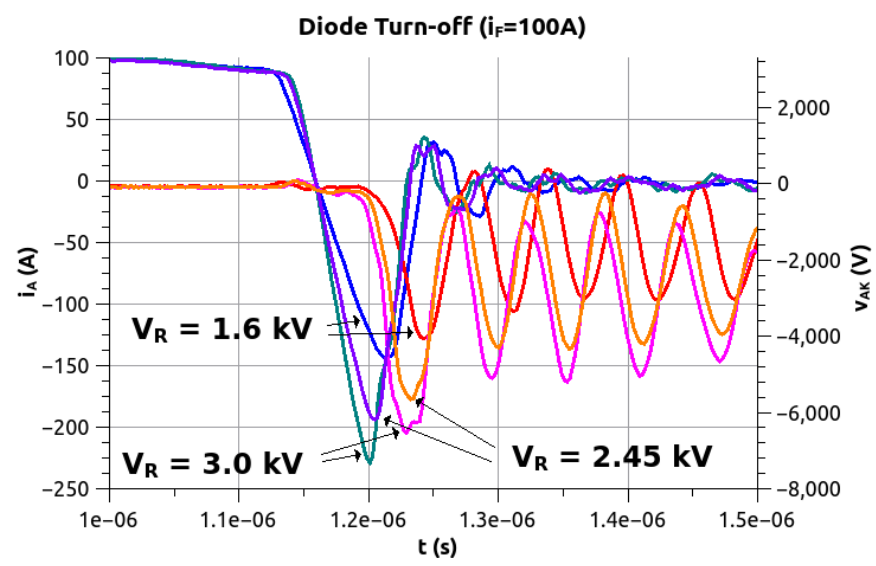

Fig. 7 - DPT turn-off measurements for different reverse applied voltage $V_{R}(1.6$ to $3.0 \mathrm{kV})$ for a forward current $\mathrm{I}_{\mathrm{F}}=100 \mathrm{~A}$.

The fabricated bipolar diodes show good switching performances with $\mathrm{t}_{\mathrm{rr}}$ about $90 \mathrm{~ns}$ at $100 \mathrm{~A}$ and $2 \mathrm{kV}$.

High current Stress. The repetitive high current used to stress the devices were $10 \mathrm{~ms}$ half-sine pulses with 100 A peak. After 10000 pulses at different temperatures, static measurements are carried out to plot the evolution of different electrical parameters $\left(V_{t h}, R_{o n}\right)$. The extracted data are given in the following table.

Tab. 1 - Dynamic resistance and threshold voltage of the diode for different temperatures.

\begin{tabular}{|c|c|c|c|c|}
\hline Temperature $\left({ }^{\circ} \mathrm{C}\right)$ & \multicolumn{2}{|c|}{ Dynamic resistance $(\mathrm{m} \Omega)$} & \multicolumn{2}{c|}{ Threshold voltage @ 0,5 A (V) } \\
\cline { 2 - 5 } & before & after & before & after \\
\hline 50 & 513 & 503 & 2,93 & 2,94 \\
\hline 100 & 526 & 530 & 2,87 & 2,88 \\
\hline 175 & 616 & 609 & 2,76 & 2,76 \\
\hline
\end{tabular}


The forward and reverse characteristics before and after the 10000 high current pulses are shown in Fig. 8 and Fig. 9 respectively. It seems that stressing the device doesn't alter its forward performance.

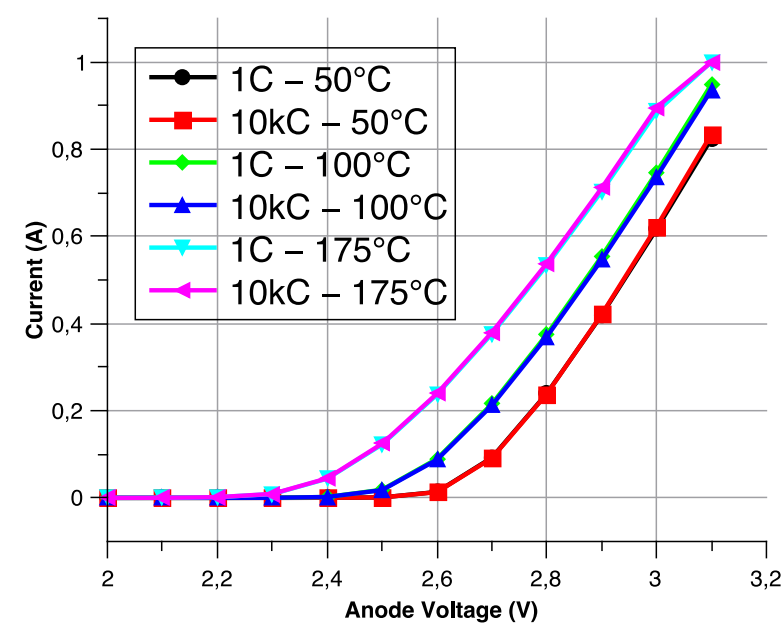

Fig. 9 - Forward characteristics at increasing temperature after stress.

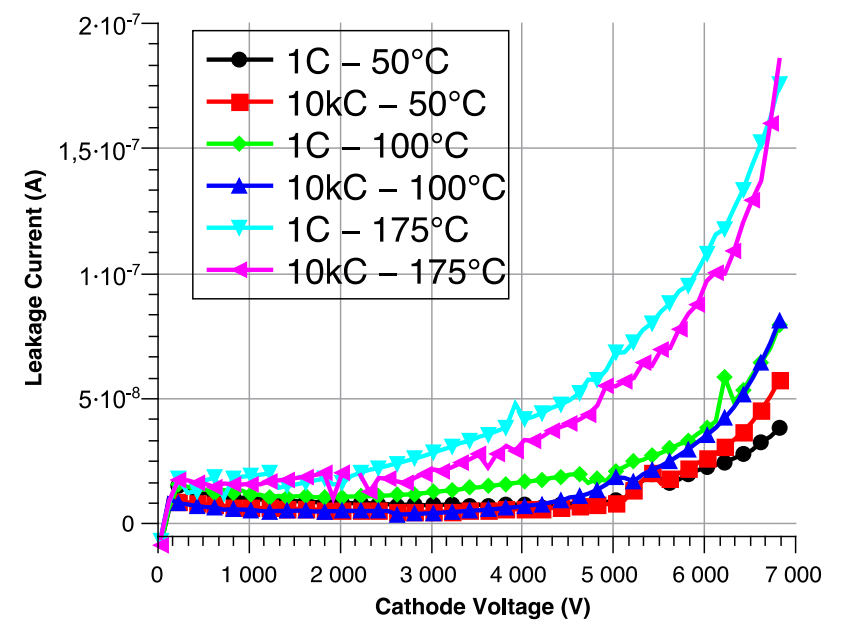

Fig. 10 - Reverse characteristics at increasing temperature after stress.

Neither the resistance, nor the threshold voltage seem to be affected by the high current stress. Whereas the reverse characteristics seems to be improved by the cycling at higher temperature. The leakage current is lower after the cycling for $100^{\circ} \mathrm{C}$ and $175^{\circ} \mathrm{C}$, but at this stage it can not be attributed to the stress itself. The effect may be as well a consequence of high temperature stress during a long time, which could relieve mechanical stress and affect the trapped charge at the interface between oxide and JTE. Further tests are necessary to determine the origin of the leakage current improvement. Nevertheless, the stress has almost no effect on the device, which is an indicator of its outstanding robustness.

\section{Summary}

The actual blocking voltage is $80 \%$ of the $10 \mathrm{kV}$ aimed breakdown voltage. Static and switching characteristics show good performances. According to the results, it seems that there is no degradation of the static electrical characteristics after stress. The slight improvement of the leakage current is not necessarily an effect of high current, but can be a consequence of high temperature stress. In the future studies, higher current levels will be used for stress tests and the effect on both static and switching performance will be analysed.

Acknowledgements: SuperGrid Institute for providing the devices and funding.

\section{References}

[1] D. Johannesson et al. Potential of ultra-high voltage silicon carbide semiconductor devices WiPDA 2016.

[2] Deep Concept, Tarbes, France, http://www.deepconcept.fr/

[3] B. Asllani, J. B. Fonder, P. Bevilacqua, D. Planson, L. V Phung, and P. Brosselard, "Surge Driven Evolution of Schottky Barrier Height on 4H-SiC JBS Diodes," Mater. Sci. Forum, vol. 924, pp. 593-596, 2018.

[4] Z. Chen, D. Boroyevich, R. Burgos, et al. Characterisation and modeling of $1.2 \mathrm{kv}, 20 \mathrm{~A}$ SiC MOSFETs. In : Energy Conversion Congress and Exposition, 2009. ECCE 2009. IEEE. IEEE, 2009. p. 1480-1487.

[5] H. Garrab, B. Allard, H. Morel, K. Ammous, S. Ghedira, A. Amimi, K. Besbes, J.-M. Guichon, « On the Extraction Procedure of PIN diode Design Parameters for validation of Integrated Power Converter Design », special issue on integrated power electronics, IEEE Trans. On Power Electronics, Vol. 20, No. 3, pp. 660-670. 2005. [hal-00140858], doi: 10.1109/TPEL.2005.846544

[6] Comeca company: http://www.comeca-group.com/en 